\title{
Systemic health reform and physician wage freeze urged for Ontario
}

$\mathrm{T}$ he province of Ontario should undertake a systemic shift in the provision of health services toward patient-centred, continuumcoordinated, preventive, communitybased care, while immediately imposing a wage freeze for physicians, according to the Commission on the Reform of Ontario's Public Services.

"The ideal health system would put more emphasis on preventing poor health. It would be patient-centric and would feature co-ordination along the complete continuum of care that a patient might need," according to the health chapter (www.fin.gov.on.ca/en/reform commission/chapters/ch5.html) of the long-awaited report on recommended measures to eliminate Ontario's \$16 billion budget deficit. Headed by Don Drummond, former chief economist with the TD Bank, the commission carefully skirted issues of privatization, while urging 105 specific measures to constrain the growth rate of Ontario's current $\$ 44.77$ billion health budget to $2.5 \%$ per year through $2017 / 18$ and then no more than $5 \%$ thereafter.

At the core of those recommendations lies the proposition that the system needs transformative change. "Primary care would be the main point of contact with patients, with much of the co-ordination across caregiving done through the administration of regional health authorities," the report argues. "There would be much less emphasis on treating patients in hospitals, which are costly and expose people to contagious diseases while yielding poor patient satisfaction. To a much greater degree, care would be provided by primary care facilities, through better information and, in the case of chronic health issues, in the home or long-term care facilities. The system would allow all professionals to exercise the full scope of their skills in their work; nurses, for example, would do what they could competently do, like administer vaccines, and nurse

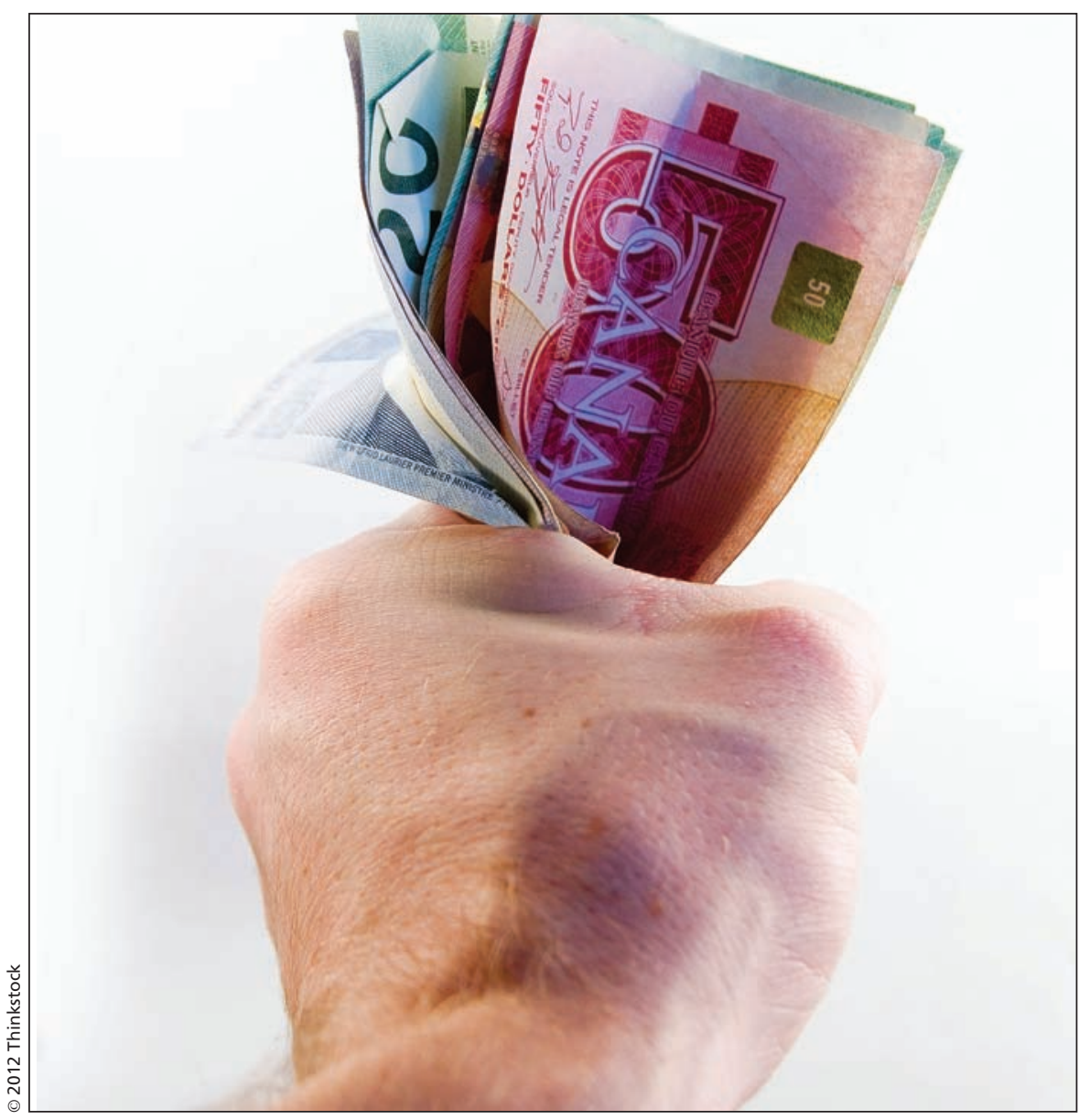

An Ontario reform commission is urging that the province become more tight-fisted with payments to doctors by imposing a wage freeze.

practitioners could provide high-quality management of chronic illnesses like diabetes and high blood pressure."

"In this ideal system, payment schemes and information gathering would be aligned to support the patientcentric notion. Compensation for hospitals and physicians would be more closely tied to outcomes of health rather than to the inputs or services. Data would be gathered on the actual total cost of looking after a patient rather than the present system of collecting data for separate portions of the system; even then, current data are actually based on government reimbursement rates rather than true costs."
Within such a reformed system, "funding to providers should be based primarily on meeting the needs of patients as they move through the health care continuum."

More immediate is the call for a wage freeze in forthcoming government negotiations on a new contract with the Ontario Medical Association. "The government must be very strategic in its objectives to ensure the promotion of a high-quality care system that runs efficiently. Since Ontario's doctors are now the best paid in the country, it is reasonable to set a goal of allowing no increase in total compensation. However, the negotiations must go well 
beyond compensation. They must also address the integration of physicians into the rest of the health care system and the objective of working towards the best possible health quality regime."

$\mathrm{He}$ also urged that provincial costs for physician services be a blend in which $70 \%$ of doctors are paid through salary/capitation and 30\% through feefor-service; that fee schedules reflect technological innovation, with the savings poured back into the system; that compensation and performance pay be directly linked to "strategically targeted health outcomes," rather than the number of interventions performed; and that more physicians be nudged into family health teams, which should become "the norm for primary care" with oversight of their medical services falling under the rubric of the province's 14 Local Health Integration Networks (LHINs).

The LHINs should be "reconstituted" and given more authority over decision-making, as well as adequate funding, to ensure that the delivery of health care in Ontario be organized along "regional" lines.

Moreover, they should have "clear powers to deal with all aspects of the health system's performance in their area, including primary care (physicians), acute care (hospitals), community care and long-term care. This would include setting budgets and/or compensation for all players."

Other health-related recommendations included:

- Limit the input of physicians in determining what constitutes a medically necessary service covered by the Ontario Health Insurance Plan (OHIP). Determining those services through periodic negotiation with the Ontario Medical Association must "stop. As in other jurisdictions, doctors should be consulted on such questions, but no more." Shift responsibility for making that determination of covered services to Health Quality Ontario.

- "Where feasible," shift the delivery of such services as vaccinations to "lower-cost" caregivers, such as nurses, physician assistants and nurse practitioners.

- Revise support for hospitals to become a system based on a mix of activity-based and base funding, rather than one based on "average costs."

- Further amalgamate hospitals and reduce the number of hospital boards.

- Expand the scope of practice of pharmacists by allowing them to "administer routine injections and inhalations, including immunization," while also allowing them more liberty to utilize "therapeutic substitution" to fill physician prescriptions with less expensive drugs.

- Implement a series of measures designed to provide more medical services through community, home and long-term care facilities, rather than hospitals.

- Expand the use and role of patient navigators and hospitalists in case management.

- Adopt "interprofessional, team-based approaches" in the management of complex and chronic conditions.

- Work with other provinces to establish "a national entity that would set a common price for pharmaceuticals for the entire country."

- Link the Ontario Drug Benefit Program, which cover drugs for seniors and social assistance recipients, "directly to income."

- Compel physicians in family health teams to "begin engaging in discussions with their middle-aged patients about end-of-life health care."

- Overhaul management, funding and oversight of public health services.

- "Accelerate the adoption of electronic records, working in a bottomup fashion."

- "Reduce absenteeism for Ontarians and office visits, while improving patient satisfaction, through secure messaging between patients and providers, online appointment scheduling, access to test results for patients, and online requests for prescription refills and renewal."

Drummond, a known advocate of privatization in the delivery of health services, and his commission had been instructed to avoid recommendations that urged privatization. But while the report does not make a point-blank recommendation that a private, parallel system be allowed, it does recommend an expansion of private, for-profit medicine. Medical services, it states, "could be provided by private, for-profit entities, but operated within the public payer system. Government would continue to determine what services are offered and set the fees paid by OHIP. The patient experience would, however, remain the same: upon presentation of a health card, the government will pay for the services rendered."

When the commission was created in the 2011 provincial budget, the government billed it as an examination of "long-term fundamental changes to the way government works. The Commission's work will include exploring which areas of service delivery are core to the Ontario government's mandate, which areas could be delivered more efficiently by another entity and how to get better value for taxpayers' money in the delivery of public services" (www.fin.gov.on .ca/en/budget/ontariobudgets/2011/ch1b .html\#c1_secB_sizeReduction).

But the government was also careful to constrain its mandate, stating that "the Commission will not make recommendations that would increase taxes or lead to the privatization of health care or education."

The latter stipulation was aimed at allaying fears that the appointment of Drummond to head the commission was an invitation for a call for more privatization of the health care system. In 2010, he had authored a report, Charting a Path to Sustainable Health Care in Ontario, for the province's health department that recommended the government "throw the door open more widely to private-sector involvement" including private-for-profit delivery of primary care and two-tier delivery of elective surgeries (www.td .com/document/PDF/economics/special /td-economics-special-db0510-health -care.pdf).

"As long as the public can use their OHIP card they would probably support the underlying services being provided in whatever manner is most efficient. There should not be any inherent bias against public provision of services. The key is to determine the service model that delivers the best combination of quality and cost," Drummond's report argued. - Wayne Kondro, CMAJ

CMAJ 2012. DOI:10.1503/cmaj.109-4130 